\title{
CIDADANIA E DIREITOS
}

\author{
CITIZENSHIP AND RIGHTS
}

Daniela Mesquita Leutchuk de Cademartori*

Resumo: Este ensaio trata dos usos históricos e conceituais da cidadania, examinando em específico seu vínculo com a nacionalidade a partir do Estado liberal e o processo de positivação dos direitos humanos a partir das contribuições do filósofo Jürgen Habermas ao tema. Pretende-se analisar as possibilidades de permanência deste conceito como "marco de referência" para a participação democrática nos processos jurídico-políticos que envolvem os Estados de direito das sociedades complexas atuais. Somente uma cidadania, garantida pelos direitos fundamentais das atuais Constituições democráticas, que se manifesta através de processos de formação de opinião informais e de uma "vontade mais ou menos discursiva" é compatível com uma pluralidade cultural e individual coletiva.

Palavras-chave: Cidadania; Direitos Humanos; Direitos Fundamentais; Nacionalidade; Jürgen Habermas.

Abstract: This essay deals with the historical transformations of the concept of citizenship, exams in particular its link with nationality from the liberal state and the process of legal recognition of human rights from the contributions of the philosopher Jürgen Habermas to the subject. It's intend to examine the possibilities of the concept as "a benchmark" for democratic participation in legal and political processes of the rule of law in complex societies today. Only a citizenship, guaranted by the fundamental rights of the current democracy constitutions, wich manifests itself through processes of opinion formation and informal "will more or less discursive" is compatible with a cultural diversity and individual conference.

Key words: Citizentship; Nationality; Human Rights; Fundamental Rights; Jürgen Habermas.

\section{Introdução}

Parte-se da constatação de que historicamente a noção de cidadania tem, através dos tempos, mantido sua força, designando o vínculo jurídico que une as diferentes formas de organização política a seus membros, cabendo a partir da Modernidade à teoria dos direitos

\footnotetext{
* Possui graduação em Direito e em História pela Universidade Federal de Santa Maria (1986 e 1984), pósgraduação (lato sensu) em fundamentos de epistemologia pela Universidade de Santa Cruz do Sul (1985), Mestrado e Doutorado em Direito pela Universidade Federal de Santa Catarina (1993 e 2001). Atualmente é docente do Centro Universitário La Salle (Unilasalle -Canoas - RS) e professora vinculada ao Programa de Mestrado Direito e Sociedade da Unilasalle de Canoas - RS. Conselheira editorial das revistas Novos Estudos Jurídicos, Sequência, CEJ (Centro de Estudos Juridicos do Conselho da Justiça Federal), Juris Poiesis (UNESA), Pensar (UNIFOR), Direito, Estado e Sociedade (PUC-RJ), Espaço Jurídico/Espaço Jurídico Journal of Law, Revista do Centro Acadêmico Afonso Pena (UFMG) e consultora externa da Universidade Norte do Parana. Tem experiência na área de Direito, com ênfase em Teoria Política, Filosofia do Direito e História do Direito, atuando principalmente nos seguintes temas: teoria política constitucional, história do direito, democracia, direitos fundamentais sociais, cidadania, bens fundamentais (em especial a água), novo constitucionalismo latino-americano e dignidade da pessoa humana. Editora da Revista Novos Estudos Jurídicos (Qualis=A2) durante os anos de 2002 a 2008.
} 
fundamentais organizar seus diferentes significados. Com esta mudança, a ex fundamental rights pressão passou a designar o vínculo jurídico de pertencimento a um Estado de Direito aludindo especificamente aos direitos políticos ou de participação imediata de seus titulares na vida estatal. Pretende-se aqui analisar os limites e possibilidades de sua permanência como "marco de referência" para a participação democrática nos processos jurídico-políticos de um Estado de Direito que pretende ultrapassar as fronteiras do estrito nacionalismo.

Estado de Direito, direitos fundamentais e cidadania, três categorias jurídicopolíticas, condicionam-se e implicam-se mutuamente, tendo emergido no mesmo ambiente histórico. O Estado de Direito é a forma política na qual os poderes atuam divididos e submetidos ao império da legalidade que garante os direitos fundamentais e a cidadania. Já os direitos fundamentais são o fundamento de legitimidade do Estado de Direito e o conteúdo da cidadania. E, por último, a cidadania é o espaço de participação política no Estado de Direito, através do exercício dos direitos fundamentais.

O processo histórico de ampliação da cidadania deixa evidente o seu caráter de construção e de luta por direitos, caráter esse que se configura em seu conceito contemporâneo. Na atualidade, se por um lado, ela é um conjunto de direitos civis, políticos e sociais, por outro, um sentimento comunitário de participação e, portanto, significa a exclusão dos integrantes que não comungam com esses sentimentos. Se todo cidadão necessariamente é membro de uma comunidade específica - seja qual for a sua organização - tal pertencimento é fonte de obrigações, ao mesmo tempo em que é também lócus de reivindicação de direitos. No cerne do conceito de cidadania subjaz seu caráter público e impessoal, de espaço e meio no qual conflitam aspirações e desejos dos grupos sociais, transformados em ações coletivas, que integram a comunidade, tendo como objeto a construção de projetos futuros.

A análise histórico-conceitual da relação entre cidadania e nacionalidade, bem como dos aportes teóricos ao tema de Habermas se convertem em um pretexto para o esclarecimento de alguns pontos de vista normativos, a partir dos quais se pode compreender melhor a complexa relação estabelecida entre a cidadania e a identidade nacional. Com isto, acaba-se por perceber que o debate em torno do tema sofreu uma nova guinada com acontecimentos tais como a "Queda do Muro de Berlim" (1989) e os subseqüentes, ocorridos no Leste Europeu. Se a democratização do Estado teve como base a homogeneidade cultural e étnica propiciada pelo Estado-nacional, a atual perda dos significados pré-políticos que revestem esse Estado poderia apontar para um enfraquecimento desse fenômeno? Se a resposta não pode ser dada sem que se incida em futurologia - e conforme Bobbio, o ofício do profeta é perigoso $^{\mathrm{i}}$ - desde já é possível constatar que a dissolução da forma clássica do R. Fac. Dir. UFG, v. 37, n. 1, p. 73 - 93, jan. / jun. 2013 
Estado nacional também acarreta a dissolução das chaves semânticas que definem a cidadania e a identidade nacional.

\section{Sobre o conceito de cidadania}

O jurista espanhol, Antonio-Enrique Pérez Luño menciona a existência, no interior das teorias analítico-lingüísticas sobre a cidadania, das definições lexicais ${ }^{\mathrm{ii}}$. Nesta perspectiva, considerando a definição de cidadania, é possível perceber os seguintes pares: descritivo e prescritivo, teórico e pragmático, natural e político, global e local, universal e particular e os pares unilateral e multilateral. (2002; p. 162)

Definições descritivas de cidadania são aquelas adotadas pelos constitucionalistas e administrativistas, pelas quais ela pode ser traduzida num conjunto de normas que regulam o status jurídico dos cidadãos. Sendo assim, a categoria emana do direito positivo estatal e para sua definição contribuem a análise empírica e a exegese deste setor normativo do ordenamento jurídico.

Por outro lado, definições prescritivas são aquelas em que a noção reveste-se de um significado deontológico, enquanto modelo ideal de status que deveria ser reconhecido aos membros da sociedade política ${ }^{\mathrm{iii}}$.

A utilização teórica da noção de cidadania é concretizada através dos aportes doutrinais multidisciplinares da filosofia, do direito, da sociologia, etc., enquanto a intencionalidade pragmática é percebida naqueles que invocam a mesma como bandeira de luta na consecução de determinadas liberdades. A última situação pôde ser percebida no movimento em favor dos direitos civis na segunda metade do século passado ou mesmo na luta contra o apartheid. Importa salientar que a versão teórica da cidadania não exclui sua possível dimensão pragmática. (PÉREZ LUÑO: 2002; p. 162, 181)

A contraposição entre as definições naturais e políticas de cidadania deriva da diferenciação produzida pelos primeiros tipos de definição. Elas surgem a partir das teorias contemporâneas de orientação comunitarista que concebem a cidadania como um fator inato e necessário que determina a inserção do indivíduo em um grupo étnico e/ou cultural ${ }^{\mathrm{iv}}$. Conseqüentemente, tais definições opõem-se às concepções liberais - tais como a de John Rawls - que a percebem como um conceito estritamente político, isto é, um vínculo decorrente da relação contratual (pacto social) e da adesão livre das pessoas à sociedade.

Para Pérez Luño, a acepção natural de cidadania, tem como pressuposto ideológico e se inscreve na tradição nacionalista herderiana, enquanto o ideal político de R. Fac. Dir. UFG, v. 37, n. 1, p. 73 - 93, jan. / jun. 2013

ISSN 0101-7187 
cidadania sustentado pelo pensamento liberal tem como antecedente o humanismo cosmopolita kantiano ${ }^{\mathrm{v}}$.

Por seu turno, a percepção global de cidadania é sustentada por aqueles que a concebem como o conjunto de todos os direitos fundamentais, uma noção que compreende não só os direitos civis e políticos como também os econômicos, sociais e culturais ${ }^{\mathrm{vi}}$. Como para um amplo setor da doutrina juspublicista a cidadania possui uma significação limitada ficando circunscrita a seu sentido técnico-jurídico implicado pela determinação da qualidade de cidadão ou do vínculo de pertencimento a uma determinada organização política e os consequientes direitos de participação democrática - é possível opor à definição global uma definição local da mesma ${ }^{\text {vii }}$.

É possível também apontar, em determinadas teorias, a proposta de uma cidadania tão ampla a ponto de fazê-la coincidir com um status universal. ${ }^{\text {vii }}$

Este último significado apresenta uma grande afinidade com a noção política, sendo incompatível com a sua acepção natural. (PÉREZ LUÑO: 2002; p. 181)

Por outro lado, são mais freqüentes as concepções particulares da cidadania, a começar pela tradição doutrinária do direito público que a faz coincidir com idéia de pertencimento a um Estado. ${ }^{\text {ix }}$

Se por muito tempo o uso lingüístico do termo cidadania fazia referência a um vínculo único e exclusivo entre o indivíduo e o Estado, nas circunstâncias atuais é possível admitir uma pluralidade de cidadanias. Em outros termos, substituir a cidadania unilateral por uma cidadania multilateral. ${ }^{\mathrm{x}}$

Cabe lembrar que esta classificação não é estanque, sendo possíveis usos lingüísticos descritivos da cidadania, ao mesmo tempo que teóricos, políticos, globais, universais e multilaterais.

A fim de que a cidadania não sofra uma diminuição em sua função jurídicopolítica e na sua capacidade de potencializar a participação democrática nos atuais Estados de direito, a análise lexical precisa ser completada pelas análises explicativas ${ }^{\mathrm{xi}}$. Uma das manifestações destas definições - ao lado da sistemática ${ }^{x i i}$ - é a histórica. Ela indaga sobre a evolução diacrônica dos termos nos momentos mais decisivos para a conformação de seu significado atual, o que será feito a seguir.

\section{A história do vínculo entre cidadania e nacionalidade}

\subsection{O Iluminismo}


Não há como escapar da constatação de que o atual sentido de cidadania é conformado historicamente pelo Iluminismo. ${ }^{\text {iii }}$

Esse movimento, estruturador do mundo político moderno, inventou a noção de indivíduo $^{\text {xiv }}$ como ponto de partida e fundamento do fenômeno político, postulando-o como titular de direitos, não mais derivados do grupo social de origem, e sim, próprios.

Nesse sentido, pode-se observar a sincronia entre a aparição do conceito moderno de cidadania e o conceito dos direitos humanos e do Estado de Direito, cujo reconhecimento também deve ser situado no âmbito da Modernidade ${ }^{\mathrm{xv}}$.

A tendência de considerar cidadania e direitos humanos de modo conjunto é recente: a análise histórica dos termos mostra que enquanto a cidadania tem origem na Antiguidade a cultura dos direitos tem origem na Modernidade. ${ }^{\text {xvi }}$

De artigos políticos da Enciclopedia, devidos a Denis Diderot e Jean Le Rond d'Alembert, é possível extrair uma definição explicativa da cidadania em chave histórica e sistemática. Pérez Luño deriva da idéia de cidadania três grandes princípios: 1. A cidadania é uma condição de uma pessoa que vive em uma sociedade livre. Para que esta condição seja efetivada é necessária a existência prévia de uma ordem política democrática, capaz de garantir o exercício destas liberdades. 2. A cidadania é uma condição voluntária, não pode ser imposta às pessoas. O pacto social funda a cidadania como um acordo livre de pessoas para integrar um determinado modelo de organização política ${ }^{x v i i}$. 3. A cidadania se desdobra em um conjunto de direitos e deveres das pessoas que pertencem a um determinado Estado. Aqueles que não são cidadãos - mulheres, crianças e servos - participam da condição através dos vínculos que os unem com aqueles que ostentam tal condição. (PÉREZ LUÑO: 2002; p. 184)

No início da Idade Moderna, as lutas que culminaram na Declaração dos Direitos do Homem nos Estados Unidos e na França operaram, no dizer de Bobbio, uma "verdadeira revolução copernicana", rompendo o princípio de legitimidade então vigente e instaurando a concepção moderna de cidadania. Se anteriormente, o princípio de legitimidade baseava-se nos deveres dos súditos, a partir destes acontecimentos, passava a basear-se nos direitos do cidadão. (1992; p. 3)

Há que lembrar que a Revolução Francesa - marco emblemático da Ilustração foi uma revolução de cidadãos: a cidadania era o centro de imputação de um conjunto de direitos e liberdades que correspondem aos membros de um Estado de Direito. É possível afirmar que neste período ela teve o seu significado recuperado, ao mesmo tempo, que "corroído".

R. Fac. Dir. UFG, v. 37, n. 1, p. 73 - 93, jan. / jun. 2013 
Para Fábio Konder Comparato, o problema político-ideológico surgido por ocasião da instalação da Assembléia Nacional Francesa (1789), foi suscitado pela confluência de duas correntes de pensamento. A primeira, defendia a universalidade da Declaração dos Direitos, daí a preferência pelo termo "homem" ao invés do termo "cidadão". A segunda corrente de pensamento, influenciada de uma ou outra forma por Rousseau, parte do pressuposto de que diferentemente do "estado de natureza", no "estado civil", os direitos expressão da vontade geral - são fixados em lei. Conseqüência desse conflito de posições, refletido na controvérsia oitocentista do positivismo jurídico, será a fórmula de compromisso adotada pela Declaração de 1789: "direitos do homem e do cidadão". Desse modo a cidadania que surge na Idade Moderna comportou desde o início, as dimensões nacional e universal. "Todo homem é doravante, protegido em seus direitos naturais, independentemente de sua nacionalidade, mas somente os nacionais são titulares de direitos políticos.” (1993; p. 89)

A inovadora Constituição jacobina (1793) em seu artigo $4^{\circ}$. ao definir o status dos cidadãos chegou a garantir a todo estrangeiro adulto, residente a um ano na França o direito de permanecer no país e a cidadania ativa. Assim, os estrangeiros passam a ter os mesmos direitos e deveres que a população nativa. (HABERMAS: 1997; p. 298)

Esta mesma Constituição apresentou pela primeira vez a noção de direitos sociais. Seu artigo 21 assim estabelecia:

Os socorros públicos são uma dívida sagrada. A sociedade deve a subsistência aos cidadãos desafortunados, seja conseguindo-lhes trabalho, seja garantindo os direitos aos meios de existência para aqueles que não tem condições de trabalhar. (apud SINGER: 2003; p. 217)

Com o Golpe do 9 Termidor do ano II (1794), ocorre uma mudança no equilíbrio das forças da Revolução Francesa, o que assinala o declínio dos jacobinos. A Constituição de 1795 acabou por formular um conceito de cidadania com uma extensão bem mais limitada em relação ao período anterior: "É cidadão quem, não sendo estrangeiro e tendo sido registrado como cidadão, paga os impostos para a manutenção do Estado." $\mathrm{Na}$ seqüência dos acontecimentos, a Constituição de $1799^{\text {xviii }}$ acabou por acrescentar novos aspectos ao instituto da cidadania. Seu conteúdo político foi esvaziado: sua aquisição passa a se dar pelo local do nascimento, estabelecendo pela primeira vez o critério jus soli, ou pela residência no território pelo período de dez anos. Essa transformação de conteúdo da cidadania acabou por implicar a consolidação do conceito de nacionalidade.

No mundo moderno, a liberdade consiste, além de participar da gestão da coisa pública, em não ser molestado abusivamente pelo Estado na vida privada. Essa independência 
individual é um fato inédito na história e "corresponde não propriamente a uma servidão política, mas a um estado de passividade.” (COMPARATO: 1993; p. 89)

Como corolário, ocorre uma ruptura entre a cidadania civil e a política. A primeira é compreendida como soberania individual e a segunda como delegação da soberania política. Para Benjamin Constant essa delegação era na realidade uma "abdicação". (CONSTANT: 1980; p. 259)

Na cidadania moderna a eleição apenas dá o consentimento do eleitor ao eleito para que esse último exerça uma função pública determinada. O eleito não precisa agir por conta e no interesse dos eleitores: o mandato não é vinculado. ${ }^{\text {xix }}$

A solução foi estabelecer a completa separação entre o mandato civil e o político e ocorreu no curso da Revolução Francesa. Os eleitos eram representantes da nação e não das pessoas que os elegeram. No artigo $3^{\circ}$. da Declaração dos Direitos do Homem e do Cidadão ficou estatuído que "o princípio de toda soberania reside essencialmente na nação; nenhuma entidade, nenhum indivíduo pode exercer algum poder que não emane, expressamente da nação”. Para Fábio Konder Comparato,

Não há dúvida que a fórmula assim encontrada procurou levar em conta as duras
críticas de Rousseau à possibilidade de uma representação da soberania. A 'vontade
geral', da qual a lei é a legítima expressão, corresponde ao interesse nacional. Mas
feita assim essa homenagem às idéias do grande genebrino, a maioria sentiu-se em
posição mais confortável para repudiar as propostas jacobinas de admissão do
mandato imperativo e da revogação popular de mandatos. (1993; p. $90-1)$

Se por um lado, a "nação", titular da soberania, só pode exercê-la através da manifestação da vontade do povo, por outro, este último não é composto só por pessoas juridicamente capazes. Pelas convicções do século XVIII e XIX, nem todos os homens com plena capacidade jurídica estavam aptos a serem eleitos. A Constituição francesa de 1791, seguida por outras no século seguinte, estabeleceu um sistema de eleição indireta para o legislativo $^{\mathrm{xx}}$.

O sufrágio universal, com a extensão do direito de voto às mulheres e aos analfabetos, não modificou o esquema de modo substancial. Isso porque, politicamente, os cidadãos do Estado liberal não podem intervir diretamente no funcionamento das instituições públicas, condenados que estão à passividade. O exercício da soberania encontra-se monopolizado pelos representantes eleitos. Conforme salientou Benjamin Constant, o cidadão da era moderna teve que pagar este preço para resgatar a sua liberdade privada. 
Em suma, no século XIX, a cidadania, com o seu conteúdo político neutralizado não era mais pressuposta uma "interpretação substancial" do cidadão como membro desta comunidade - passa a associar-se de modo definitivo à nacionalidade.

\subsection{Cidadania e nacionalidade}

Jürgen Habermas ressalta o fato da democracia e do Estado nacional nascerem como "irmãos gêmeos" a partir da Revolução Francesa, isto é, de se encontrarem "à sombra do nacionalismo". O modelo francês de Estado territorial, administrado por um poder central, é aquele que acaba por estruturar, a longo prazo, o sistema de Estados europeus. Se no início ele toma a forma de reinos, a "democratização provocada" por este modelo foi produzida na medida em que ele se configura como Estado nacional. ${ }^{\text {xxi }}$

É assim que, o nacionalismo ou a consciência nacional constitui uma manifestação especificamente moderna da integração cultural. Uma tal consciência política de pertencimento a uma nação determinada corresponde a uma dinâmica que só atingiu a população quando ela foi individualizada e mobilizada pelos processos de modernização econômica e social que a libertaram dos "laços sociais corporativos". A mobilização também se dá através da mediação literária e pela mídia, conferindo ao nacionalismo características artificiais e muitas vezes "tornando-o presa fácil do abuso e da manipulação através das elites políticas.” (HABERMAS: 1997; p. 281-2)

Contudo, a união entre cidadania e nacionalidade não seria tão pacífica, eis que Estado liberal e Estado-nacional possuem conceitos distintos e contrapostos de nação. Todo nacionalismo representa uma exaltação de características específicas identidárias nacionais, postuladas como uma ideologia ou cosmovisão política, o que é incompatível com o liberalismo. (PÉREZ LUÑO: 2002; p. 195)

Habermas lembra que o primeiro significado do conceito de nação está relacionado às gens ou comunidades não integradas politicamente. ${ }^{\text {xii }} \mathrm{O}$ segundo significado surge no início da Modernidade e estabelece a nação como titular de soberania. Em meados do século XVIII esses significados se entrelaçam para, a partir da Revolução Francesa, o termo nação passar a designar a fonte da soberania do Estado (Siéyès) e com isso o complexo étnico cede lugar à comunidade democrática intencional.

No final do século XIX a nação passa a ser percebida em um contexto voltado para o nacionalismo. “A identidade da nação de cidadãos não reside em características étnico- 
culturais comuns, porém na prática de pessoas que exercitam ativamente seus direitos democráticos de participação e comunicação.” (HABERMAS: 1997; p. 282-283)

Um nacionalismo adquirido surge de um nacionalismo herdado, assim como uma relação complementar originária se estabelece entre nacionalismo e republicanismo. O nacionalismo "conseguiu promover a identificação do indivíduo com um papel que exige uma grande dose de engajamento pessoal, podendo chegar, inclusive, ao sacrifício de si mesmo: o serviço militar obrigatório para todos constitui apenas a outra face dos direitos dos cidadãos!" (HABERMAS: 1997; p. 283)

Todavia, em nível conceitual a cidadania independe da identidade nacional, eis que a liberdade nacional de auto-afirmação coletiva contra nações estrangeiras não é a mesma liberdade genuinamente política dos cidadãos de um país. ${ }^{\text {xiii }}$

Ocorre que esse processo democrático de formação da opinião transforma-se na própria constituição do Estado de Direito, não gerando apenas uma unidade resultante de uma homogeneidade preliminar da descendência ou da forma de vida.

Cada homem e cada mulher deve ser alvo de um tríplice reconhecimento, ou seja, devem encontrar igual proteção e igual respeito em sua integridade: enquanto indivíduos insubstituíveis, enquanto membros de um grupo étnico ou cultural e enquanto cidadãos, ou membros de uma comunidade política. (HABERMAS: 1997; p. 284-285)

Só recentemente, na linguagem dos juristas a cidadania deixou de significar apenas o sentido de nacionalidade e foi ampliada no sentido de um status de cidadão envolvendo direitos. Como a auto-compreensão do Estado Democrático de Direito envolve o princípio da voluntariedade, as características convencionais do jus soli e do jus sanguinis são insuficientes para fundamentar uma submissão irrevogável ao poder soberano do Estado. "Elas constituem apenas critérios administrativos que permitem supor um assentimento implícito, o qual corresponde ao direito de emigrar ou de renunciar à cidadania." (HABERMAS: 1997; p. 285)

\section{A cidadania das Constituições democráticas}

Posturas teóricas que propugnam a abolição do conceito de cidadania devem ser analisadas no contexto da crítica ao vínculo entre cidadania e nacionalidade e do surgimento de uma cidadania transnacional, contexto em que emerge a fragmentação desse conceito. Dentre elas, merece destaque a argumentação desenvolvida por Luigi Ferrajoli que prega a superação desta noção, por considerá-la inadequada do ponto de vista da teoria jurídica além de responsável por práticas políticas indesejáveis, pois ao se substituir esta noção por outra, a nova tomaria para si a tarefa das novas exigências de titularidade e conteúdo. ${ }^{\text {xxiv }}$ 
O ponto de partida de Ferrajoli é a teoria de Thomas Marshall. Antes dele, a Declaração de direitos de 1789, havia afirmado dois tipos de direitos fundamentais: os direitos da personalidade, que correspondem a todos os indivíduos enquanto pessoas e os direitos de cidadania, que correspondem exclusivamente aos cidadãos. (Ferrajoli, 1999, 97ss, 2001, 40ss apud PÉREZ LUÑO: 2002; p. 197-8). Quando Marshall engloba direitos civis, políticos e sociais na noção de cidadania, oblitera o significado estrito da mesma enquanto um status subjetivo de titularidade dos direitos políticos, chegando a fazê-los coincidir com os direitos da personalidade.

A questão é posta por Jürgen Habermas nos seguintes termos: em uma época em que gigantescos fluxos migratórios singram o mundo, originados principalmente de regiões pobres para regiões ricas, o problema dos asilados assume uma nova importância. Acirra-se o conflito entre os princípios universalistas do Estado Democrático de Direito e as pretensões particularistas de formas de vida tradicionais. (1997; p. 279-280)

O problema é que a cidadania é hoje utilizada como instrumento para negar direitos e liberdades aos imigrantes e asilados. Assim é que Ferrajoli propugna "la superación de la ciudadanía, la definitiva desnacionalización de los derechos fundamentales y la correlativa desastatalización de las nacionalidades". (Ferrajoli, 2001, p. 43-44 apud PÉREZ LUÑO: 2002; p. 198)

Habermas, por seu turno, parte da constatação de que não há um nexo de linearidade entre Estado Democrático de Direito e modernização capitalista. No caso da Comunidade Européia essa tensão se manifesta em nível do Estado nacional, numa diferença de integração sistêmica da economia e da administração, alimentando dúvidas quanto as expectativas normativas futuras do papel do cidadão democrático ${ }^{\mathrm{xxv}}$. A questão então passa a ser a de inquirir sobre a possibilidade de configuração de uma cidadania européia em geral, no sentido de formação de uma consciência que "sente obrigações para com o bem comum europeu", mais do que as possibilidades da ação política coletiva. (HABERMAS: 1997; p. 292)

No caso de uma cidadania européia, "os cidadãos ficam cada vez mais divididos entre uma participação ativa e uma afecção passiva”. Em um nível supra, ou se se quer transnacional, são tomadas uma série de medidas em áreas vitais, que atingem um número cada vez maior de pessoas; todavia, como o papel do cidadão só está institucionalizado de modo efetivo em nível de Estado nacional, não é possível às pessoas exercer influencia sobre essas medidas. Habermas então se pergunta se esta disparidade é apenas um desequilíbrio passageiro. $^{\text {xxvi }}$

R. Fac. Dir. UFG, v. 37, n. 1, p. 73 - 93, jan. / jun. 2013

ISSN 0101-7187 
Observa-se que um número cada vez maior de pessoas adquire "direitos de acesso e de participação num número cada vez maior de subsistemas", ampliando os seus espaços de opção, tais como mercados, tribunais, cargos públicos, escolas, hospitais, teatros, meios de comunicação pública, parlamentos, etc., isto é, alcança a situação que os sociólogos chamam de inclusão. Só que esta imagem é o resultado de uma descrição neutra com respeito aos acréscimos e perdas de autonomia.

Ela não leva em conta o aproveitamento real do status de cidadão ativo, através do qual o indivíduo pode influir na transformação democrática de seu próprio status. Sabemos que somente os direitos políticos de participação podem fundamentar a posição jurídica reflexiva de um cidadão, a qual é referida a si mesma. (HABERMAS: 1997; p. 293-294)

É possível que, de modo paternalista, direitos negativos de liberdade e mesmo direitos de participação social sejam concedidos. Em princípio, Estado de Direito e Estado de Bem-Estar Social são possíveis, sem democracia. (HABERMAS: 1997; p. 293-294)

Direitos liberais e direitos sociais podem ser analisados de modo diverso conforme o ponto de vista for funcional ou normativo. Do ponto de vista funcional, direitos liberais, cristalizados historicamente em torno da posição social do proprietário privado, significam a institucionalização de um sistema econômico regulado pelo mercado; já do ponto de vista normativo asseguram a liberdade individual. Direitos sociais, do ponto de vista funcional significam a instalação de burocracias do Estado de Bem-Estar, e do ponto de vista normativo garantem pretensões de uma justa participação na riqueza social.

E tanto as liberdades individuais, como as garantias sociais, podem ser tidas como bases jurídicas para a independência social que viabiliza uma assunção efetiva de direitos políticos. Porém aqui se trata de contextos empíricos, não de contextos necessários do ponto de vista conceitual. Pois os direitos de liberdade e de participação também podem renegar o papel do cidadão, mantendo-os nos limites das relações de um cliente que se relaciona com administrações que tudo providenciam. (HABERMAS: 1997; p. 294)

$\mathrm{O}$ desenvolvimento de um sentido sistêmico próprio ao Estado e à economia institucionalizados, desenvolvidos a partir dos mesmos direitos, concretiza "a síndrome" da privatização da cidadania, e o exercício desse papel passa a se dar enquanto defesa dos interesses de clientes. Como os sistemas da economia e da própria administração estatal apresentam uma tendência a se fecharem em seus respectivos ambientes - "obedecendo apenas aos imperativos do dinheiro e do poder" - o modelo de uma comunidade que se autodetermina através da prática comum dos cidadãos fica esmorecido. É assim que pensar a integração política a partir de uma comunidade de sujeitos livres e iguais que se autodeterminam - idéia republicana -, pensada como nação etnicamente homogênea ou como 
pessoas com o mesmo destino seguindo as mesmas tradições, não se adaptaria às condições da Modernidade. (HABERMAS: 1997; p. 294)

A proposta habermasiana de um "modelo de política deliberativa" parte da constatação de que o fato do direito ser um "medium" acaba por possibilitar uma idéia bem mais abstrata da autonomia cidadã. Os direitos fundamentais acabam por fazer com que a soberania da cidadania popular retraia-se para o interior de procedimentos institucionalizados juridicamente e processos informais de formação da opinião e de uma vontade mais ou menos discursiva.

Eu parto da idéia segundo a qual existe um entrelaçamento entre diferentes formas de comunicação, as quais tem que ser organizadas de modo que possamos supor que elas são capazes de ligar a administração pública a premissas racionais e de disciplinar o sistema econômico sob pontos de vista sociais e ecológicos sem arranhar sua lógica própria. (HABERMAS: 1997; p. 295)

Para que a população consiga "fazer valer" os seus direitos de participação política, ela precisa "integrar-se num fluxo informal de comunicação pública" que se origina de uma cultura política vinculada aos ideais de liberdade e igualdade e buscar influir nele. Paralelamente, no âmbito das corporações parlamentares, as deliberações têm que estar abertas à influência de valores e temas que surgem de esferas públicas políticas que ainda não foram encampadas pelo poder. Na atualidade, a cidadania deve ser vista como ultrapassando a mera agregação de interesses individuais pré-políticos ou de um gozo passivo de direitos concedidos paternalisticamente. Tal situação é possibilitada pelo "jogo" estabelecido pela formação institucionalizada da opinião e da vontade e as comunicações públicas informais. (HABERMAS: 1997; p. 295)

A análise do autor acrescenta novos fatores, além da luta de classes, que estimulam a juridicização de novas relações de inclusão ou o surgimento e ativação dos direitos dos cidadãos, tais como as guerras e as migrações.

No caso da Europa, a imigração oriunda do Leste europeu e das regiões pobres do Terceiro Mundo é um fator que bem trabalhado poderá promover uma mobilização política e imprimir alento a movimentos sociais endógenos de tipo novo, e não só acarretar tensões sociais.

Habermas concorda com o diagnóstico de Hannah Arendt de que a face do século XX ficou marcada pelos refugiados sem pátria, destituídos de direitos. "Ou ela [a Europa] se esforça em melhorar rapidamente as condições de vida nas regiões pobres da Europa Central e do Leste - ou então será invadida por refugiados imigrantes.” (HABERMAS: 1997; p. 297) 
Há que considerar-se que a integração política dos imigrantes também depende da maneira como as populações autóctones "assimilam as conseqüências sociais e políticas da imigração". (HABERMAS: 1997; p. 297-298)

Neste ponto, o autor levanta duas questões: a primeira, de se a Comunidade Européia, frente a levas de imigrantes que ainda irão chegar à Europa, irá seguir a mesma política adotada pelos jacobinos na Constituição francesa de $1793^{\text {xxvii }}$, e a segunda, se "será possível fundamentar a prioridade dos deveres especiais - referidos à pertença a um Estado sobre as obrigações universais que ultrapassam as fronteiras dos Estados?" (HABERMAS: 1997; p. 299)

Para responder a estas questões, levanta argumentos filosóficos, distribuídos em cinco passos:

O primeiro passo considera os deveres positivos indeterminados que exigem atos de solidariedade de difícil quantificação:

Determinadas pessoas têm obrigações especiais em relação a outras pessoas que lhes são 'próximas', por serem membros da mesma família, amigos, vizinhos ou concidadãos da comunidade política ou da nação. [...] as representações consulares no exterior assumem obrigações especiais de proteger os compatriotas. (HABERMAS: 1997; p. 299)

Argumentos utilitaristas tentam fundamentar tais deveres no benefício mútuo obtido pelos membros de uma comunidade com ações recíprocas. Eles possibilitam a justificação de direitos e deveres especiais, como por exemplo, atitudes que possam prejudicar operários estrangeiros. Todavia, esses argumentos não conseguem fundamentar deveres com relação a pessoas "com pouca capacidade de realização", como por exemplo, velhos, doentes ou mesmo estrangeiros em busca de asilo.

O etnocentrismo instrumental embutido nas expectativas de proveito mútuo propõe uma política de imigração que permite o acesso de estrangeiros apenas quando houver uma perspectiva fundamentada de que eles não colocarão em risco o equilíbrio existente entre pretensões e prestações (por exemplo, no sistema de seguridade social). (HABERMAS: 1997; p. 300)

O segundo passo apresenta uma razão para que se abandone os princípios utilitaristas mencionados acima, em favor de um modelo que se apóie em "atos de coordenação de uma divisão moral do trabalho, organizada de modo centralizado". (HABERMAS: 1997; p. 300)

Por este ponto de vista, a partir de um contexto de divisão do trabalho se dá a atribuição institucional de responsabilidade a destinatários específicos que passam a atuar moralmente. Uma tal divisão moral de trabalho deve ser regulada juridicamente fazendo com 
que a distribuição de responsabilidades seja operada através das fronteiras sociais de uma comunidade jurídica. Aos governos nacionais caberão as providências para que sejam preenchidos os deveres positivos dos cidadãos com relação aos que não são membros. Todavia, todas estas colocações se ressentem de uma análise mais acurada sobre o conteúdo desses deveres. (HABERMAS: 1997; p. 301)

O terceiro passo nos argumentos filosóficos de Habermas é composto por uma abordagem imparcial, propiciada pelos aportes de John Rawls, e se afasta da perspectiva do habitante de uma região privilegiada e se coloca na perspectiva de um imigrante que busca a sua "salvação" xxviii Com sua hipótese de uma posição original, propiciada pelo "véu da ignorância”, possibilita-se que ninguém saiba sua sociedade de origem e mesmo a posição ocupada nela. No caso de uma sociedade mundial, é evidente o resultado: ao mesmo tempo em que podem ser levantadas a partir da "posição original" posições que insistem em que o direito de imigrar seja incluído no sistema das liberdades básicas por razões semelhantes às daqueles que defendem as liberdades religiosas, limitações legítimas ao direito de imigração podem ser fundamentadas a partir de pontos de vista que levantam a necessidade de evitar conflitos sociais. (HABERMAS: 1997; p. 301-302)

Já o quarto passo considera os argumentos dos comunitaristas. Para eles, “A cidadania é uma resposta à questão 'quem sou eu?' e 'o que eu devo fazer' a partir do momento em que sou introduzido na esfera pública?” (H. R. van Gunsteren apud HABERMAS: 1997; p. 302) O argumento dos comunitaristas considera então que os membros de uma comunidade são leais a ela, lealdade que se expressa pela disposição de sacrificar o ganho pessoal em benefício dos interesses da comunidade, o que pode não ser adequado às condições de uma sociedade complexa, mas que põe em relevo um componente "ético".

Como o Estado moderno representa uma forma de vida política que não se exaure na forma abstrata de uma institucionalização de princípios gerais de direito, autores como $\mathrm{M}$. Walzer pensam que o direito de uma comunidade política de assegurar sua forma de vida pode limitar o direito à imigração. "No seu entender, o direito dos cidadãos à autodeterminação inclui o direito à auto-afirmação da própria forma de vida." (HABERMAS: 1997; p. 302-303)

Finalmente, o quinto passo considera que o argumento comunitarista possibilita duas interpretações opostas. Se pelo argumento comunitarista são impostos limites normativos adicionais ao direito liberal de imigração, o sentido particularista surge na medida em que a cidadania acaba por não se vincular à noção de identidade nacional e sim a R. Fac. Dir. UFG, v. 37, n. 1, p. 73 - 93, jan. / jun. 2013 
identidades culturais determinadas, desenvolvidas na história. É assim que deve ser interpretada a condição formal para admissão à cidadania formulada por H. R. van Gunsteren, com base em H. Arendt:

O presumível cidadão tem que estar em condições e manifestar o desejo de ser um membro desta comunidade histórica particular, com seu passado e seu futuro, com suas formas de vida e instituições, no interior das quais seus membros pensam e agem. (apud HABERMAS: 1997; p. 303)

É opinião do autor que "Somente uma cidadania democrática que não se fecha, num sentido particularista, pode preparar o caminho para um status de cidadão do mundo." Como corolário, os argumentos postos por Habermas levam-no a concluir que os Estados europeus devem unir-se em torno de uma política liberal de imigração que considere que a identidade de uma comunidade política deve depender primariamente de princípios jurídicos baseados na cultura política e não em uma forma de vida étnico-cultural especial. De seu lado, a manifestação dos imigrantes deve ser a de aceitar a cultura política da nova pátria, sem que tenham que abandonar a forma de vida cultural de origem. (HABERMAS: 1997; p. 304)

Desta forma a cidadania atual, presente nas Constituições democráticas, deve ser concebida em um sentido jurídico como aquilo que possibilita, através do exercício dos direitos fundamentais, em especial os que envolvem a participação política, "uma práxis cívica" orientada funcionalmente para preservar "o marco constitucional de um processo comunicativo" com vistas a tornar possível a pluralidade cultural dos grupos e indivíduos que se encontram sob este marco. Assim, a cidadania está dirigida a conservação de uma cultura política em um Estado Constitucional Democrático compatível com uma pluralidade cultural individual e coletiva e não a conservação de uma identidade étnica ou sócio-cultural específica. (ALAÉZ CORRAL: 2008; p. 84-5)

\section{Conclusão}

Como a Cidadania não tem uma definição estanque, historicamente o seu sentido varia no tempo e no espaço, a reflexão sobre o processo histórico de sua ampliação é fundamental para que compreendamos como a questão é posta na atualidade. O que muda, de um Estado-nação para outro, não são só as regras que definem quem é ou não cidadão (ius soli ou sanguinis); também são distintos os direitos e deveres que caracterizam o cidadão em cada um deles. Em cada um desses espaços territoriais, sociais e políticos, ao longo do tempo, o conceito de cidadania tem se alterado, seja incorporando ou não os imigrantes, seja no que 
se refere ao grau de participação dos diferentes grupos, seja no tocante à proteção propiciada pelo Estado aos que dela necessitam.

A análise do processo de ampliação da cidadania deixa evidente o caráter de construção e de luta existente na configuração de seu conceito atual. O advento dos Estadosnações modernos vai alicerçar no indivíduo e a sua relação com esses entes a atribuição da cidadania. Com a Ilustração e o Estado liberal a cidadania passa a ser definida mais pela verticalidade, ou seja, diz respeito mais a um conjunto de direitos conferido por um determinado Estado soberano do que à pertinência a uma determinada comunidade. Contudo, é a noção de indivíduos livres e iguais (entre os nacionais, por suposto), que vai emprestar a marca da cidadania liberal.

Como pode ser observado, se a concepção ilustrada da cidadania foi um instrumento básico para a emancipação política dos que gozavam da condição de cidadãos, ela também supôs uma prática discriminatória na titularidade e no exercício desta condição.

Se por muito tempo o uso linguístico do termo cidadania fazia referência a um vínculo único e exclusivo entre o indivíduo e o Estado - uma relação unilateral e omnicompreensiva de toda a atividade política entre o indivíduo e o Estado - nas circunstâncias atuais leva ao reconhecimento dos fenômenos da supraestatalidade e da infraestatalidade a admissão de uma multilateralidade da ideia de cidadania. Em outros termos, substituir a cidadania unilateral por uma cidadania multilateral.

Impõe-se, nas sociedades complexas e plurais de nosso tempo, cujos Estados estão inseridos em um contexto de multiculturalidade e até mesmo de transnacionalidade, a necessidade de revisar a equação cidadão=nacional. Neste sentido, as teses sobre a fragmentação e a negação da cidadania propiciam o cenário das condições da Modernidade necessárias para pensar a integração política a partir de uma comunidade de indivíduos livres e iguais que se autodeterminam, não mais compondo uma nação homogênea etnicamente ou seguindo as mesmas tradições. Somente uma cidadania transnacional - ou como quer Pérez Luño, multilateral ou agregadora de várias cidadanias - deve ser capaz de evitar a desintegração dos atuais Estados multiculturais. Por outro lado, a fim de que os cidadãos participem politicamente, é necessário que eles integrem e influam num fluxo informal de comunicação pública originado a partir de uma cultura política vinculada aos ideais de liberdade e igualdade. Ao mesmo tempo, os parlamentos devem estar permeáveis à influência de valores e temáticas propostas nas esferas públicas políticas ainda não encampadas pelo poder, ultrapassando a percepção da cidadania como mera agregação de interesses individuais pré-políticos.

R. Fac. Dir. UFG, v. 37, n. 1, p. 73 - 93, jan. / jun. 2013

ISSN 0101-7187 
Assim, não se adapta às condições da Modernidade e não é capaz de integrar politicamente uma comunidade de sujeitos livres e iguais, uma concepção da cidadania pensada como uma nação etnicamente homogênea. O "modelo de política deliberativa" proposto por Habermas - formulado a partir da constatação de que o direito atua como um “medium”, gera uma noção de cidadania abstrata presente nas Constituições democráticas. A soberania existente na cidadania popular, através da garantia dos direitos fundamentais, acaba por manifestar-se através de processos de formação da opinião informais, bem como de uma "vontade mais ou menos discursiva", compatível com uma pluralidade cultural individual e coletiva.

\section{Referências}

ALAÉZ CORRAL, Benito. Los Condicionamientos constitucional-democráticos de la nacionalidad y la ciudadanía. In: COSTA, Pietro; ALAÉZ CORRAL, Benito. Nacionalidad y ciudadanía. Madrid: Fundación Coloquio Jurídico-Europeo, 2008, p. 49- 125

BOBBIO, Norberto. A Era dos direitos. Tradução de Carlos Nelson Coutinho. Rio de Janeiro: Campus, 1992. 217p.

Governo dos homens ou governo das leis. In: O Futuro da democracia: uma

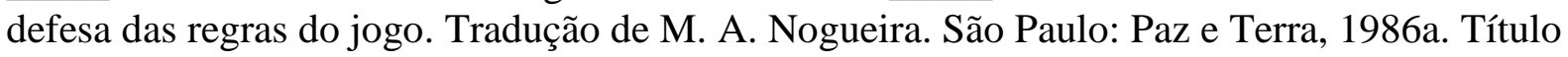
original: Il futuro della democrazia. Una difesa delle regole del gioco

Liberalismo velho e novo. In:

. O Futuro da democracia: uma defesa das regras do jogo Tradução de M. A. Nogueira. São Paulo: Paz e Terra, 1986b. p. 107- 128 Título original: Il futuro della democrazia. Una difesa delle regole del gioco.

O Futuro da democracia. In: O Futuro da democracia: uma defesa das regras do jogo Tradução de M. A. Nogueira. São Paulo: Paz e Terra, 1986c. p. 17- 40. Título original: Il futuro della democrazia. Una difesa delle regole del gioco.

Teoria geral da política: a teoria política e a lição dos clássicos. Organizado por M. Bovero. Tradução de Daniela B. Versiani. Rio de Janeiro: Campus, 2000. 717 p. Título original: Teoria Generale Della Politica

CADEMARTORI, Daniela M. L. de; CADEMARTORI, Sergio U. Mutações da cidadania: da comunidade ao Estado liberal. Revista Sequiência, Curso de Pós-Graduação em Direito da UFSC, Florianópolis, v. XXVII, n. 55, p. 65-94, dez. 2007.

COMPARATO, Fábio Konder. A Nova Cidadania. Lua Nova. CEDEC, São Paulo, n. 28/29, p. 85-106, 1993.

DUMONT, Louis. O Individualismo. Uma perspectiva antropológica da ideologia moderna. Tradução de Álvaro Cabral. Rio de Janeiro: Rocco, 1985. 
HABERMAS, J. Cidadania e identidade nacional (1990). In: Direito e democracia: entre facticidade e validade. Trad. Flávio B. Siebeneichler. Rio de Janeiro: Tempo Brasileiro, 1997. v. II, p. 299-305

MARSHALL, Thomas Humphrey. Cidadania, classe social e status. Tradução de Meton Porto Gadelha. Rio de Janeiro: Zahar, 1967. 220p. Título original: Sociology at the Crossroads and other essays

PECES-BARBA MARTÍNEZ, Gregório. Tránsito a la modernidad y derechos fundamentales. In:___ ; FERNÁNDEZ GARCÍA, Eusébio (orgs.). História de los derechos fundamentales. 1. ed., 1. reimp. rev. y cor. Madrid: Dykinson, 2003. p. 13-263

PÉREZ LUÑO, A.E. Ciudadanía y definiciones, in Doxa. Cuadernos de Filosofia del Derecho, Alicante, n. 25, p. 177-210, 2002.

RUBIO CARRACEDO, José. Introducción. In: ; ROSALES, José Maria; TOSCANO MÉNDEZ, Manuel. Ciudadanía, nacionalismo y derechos humanos. Madrid: Trotta, 2000. $231 \mathrm{p}$.

RUIZ MIGUEL, Alfonso. Ciudadanía y derechos. In: ÁLVAREZ GÁLVEZ, Iñigo et al. Teoría de la justicia y derechos fundamentales. Estudios en homenaje al profesor Gregorio Peces-Barba. Madrid: Dykinson, 2008. v. III, p. 1121-1140

SARLET, Ingo Wolfgang. A eficácia dos direitos fundamentais. 3.ed. rev., atual. e amp. Porto Alegre: Livraria do Advogado, 2003. 416p.

SINGER, Paul. A cidadania é para todos. In: PINSKY, J.; PINSKY, C. B. (orgs.) História da cidadania. São Paulo: Contexto, 2003. p. 191-263

SODER, José. Direitos do homem. São Paulo: Companhia Editora Nacional, 1960.

\footnotetext{
${ }^{\mathrm{i}}$ Ver BOBBIO, 1986c, p. 17-18

ii Definições lexicais são aquelas que segundo o autor, “ describen usos linguísticos y significados de sus términos, a partir de cómo se comprueban en la praxis linguística efectiva de las personas individuales y los grupos."(PÉREZ LUÑO, 2002, p. 178)

iiic'Este es el significado que puede atribuirse, por ejemplo, a propuesta de una 'ciudadanía diferenciada' formulada por el profesor Will Kymlicka (1996).” (PÉREZ LUÑO, 2002, p. 178)

${ }^{\text {iv }}$ Michael Walzer, em trabalho intitulado El concepto de 'ciudadanía' en una sociedad que cambia, apresenta os pressupostos básicos da concepção natural de cidadania. De acordo com ele, o liberalismo forjou uma noção formal e exterior ao sujeito de cidadania. Para o comunitarismo a cidadania é um vínculo originário e necessário de relação entre a comunidade e seus membros, transformando-a no "corazón mismo de nuestra vida". (Walzer, 2001, 162 apud PÉREZ LUÑO, 2002, p. 178)
} 
vA partir da Ilustração, a cultura e a política européias passam a ter de optar entre duas alternativas contrapostas: a humanista liberal, de estirpe kantiana, que parte da dignidade, da autonomia e da não instrumentalização dos homens livres e a tradição nacionalista, de signo herderiano, que concebe a nação ou o povo como entidade coletiva natural, dotada de espírito próprio, "cifrado en esencias irracionales que trascienden los derechos de sus componentes”. (PÉREZ LUÑO, 2002, p. 179)

${ }^{v i}$ Pérez Luño considera que esta é a versão de cidadania de Thomas Marshall. (2002, p. 179-180)

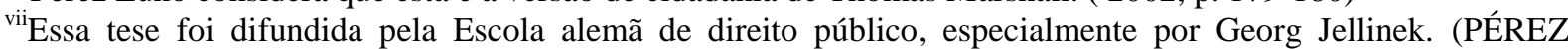
LUÑO, 2002, p. 180)

viii، En estas versiones, de inequívoca impronta cosmopolita ligadas al proyecto humanista de la modernidad, se proyecta un modelo de ciudadanía que haga posible una universales civitatis en la que se consagre plenamente el auspiciado status mundiales hominis." (PÉREZ LUÑO, 2002, p. 180) Pérez Luño posiciona-se como defensor desta definição de cidadania no plano jurídico constitucional, mencionando ser esta também a posição de autores como Peter Häberle, Fernández García e Llano Alonso. No plano filosófico-político é defendida por autoras como Martha Nussbaum. (PÉREZ LUÑO, 2002, p. 180)

ix“'Incluso en algunos estudios de Derecho municipal, se aboga por limitar, todavía más, el ámbito espacial de la ciudadanía. [...] se hace coincidir, en función de lo que su propia raíz terminológica evoca, la ciudadanía con la adscripción a la ciudad. [...] En los últimos años, se aprecia la tendencia a acentuar la vecindad civil como presupuesto básico para el ejercicio de los derechos cívicos (Rivero, 1993).” (PÉREZ LUÑO, 2002, p. 180-181)

"“El reconocimiento del desbordamiento político y jurídico del Estado a través de los fenómenos de 'supraestatalidad' (supeditación del Estado a organizaciones internacionales) y de 'infraestatalidad' (asunción de competencias jurídico-políticas por entes menores que el Estado) (Pérez Luño, 1993), invita a admitir ese uso lingüístico multilateral de la idea de ciudadanía." (PÉREZ LUÑO, 2002, p. 181)

xic Las definiciones explicativas, en el seno de la teoría analítica, se utilizan cuando se trata de establecer el significado de conceptos que se hallan en los puntos clave de una cultura, sobre los que se condensan los planteamientos y orientaciones fundamentales constitutivos de la misma." (PÉREZ LUÑO, 2002, p. 182)

xii “[...] que potencia el estudio lingüístico de los términos a partir de su análisis sintáctico, semántico y pragmático, así como su depuración de significaciones inútiles o confusas y la distinción de otras nociones análogas o afines [...]"(PÉREZ LUÑO, 2002, p. 182)

xiii $\mathrm{O}$ movimento iluminista, tem como elemento preponderante o racionalismo e compreende manifestações na esfera da cultura européia a partir do século XVIII, com grande influência nas concepções estatais e jurídicas até o século XIX. Congrega tanto características negativas - no sentido de uma tendência de libertação do indivíduo do jugo da autoridade - como características positivas, que valorizam atividades racionais e individuais independentes. De acordo com José Soder, em seus extremos ele representa a rejeição da religião tradicional e dogmática, "colocando em seu pedestal uma religião puramente moral”. (SODER, 1960, p. 58)

${ }^{\text {xiv }} \mathrm{Na}$ gênese do Estado liberal, encontramos os homens integrados e absorvidos por entes coletivos que negavam a sua liberdade e individualidade, tais como estamentos, grêmios, glebas, corporações etc. A noção moderna de cidadania, característica do Estado liberal, só emergiu na medida em que ocorre a emancipação política dos indivíduos propiciada por um pacto social garantidor da liberdade política em termos de cidadania, desobrigando os homens de vínculos políticos necessários, desiguais, fechados e naturais. (PÉREZ LUÑO, 2002, p. 195-196) Sobre a noção de indivíduo da Modernidade, ver DUMONT, Louis. O Individualismo. Uma perspectiva antropológica da ideologia moderna. Tradução de Álvaro Cabral. Rio de Janeiro: Rocco, 1985.

${ }^{\mathrm{xv}}$ Ver PECES-BARBA MARTÍNEZ, Gregório. Tránsito a la modernidad y derechos fundamentales. In: FERNÁNDEZ GARCÍA, Eusébio (orgs.). História de los derechos fundamentales. 1. ed., 1. reimp. rev. y cor. Madrid: Dykinson, 2003. p. 13-263

xvi، Frente a la ciudadanía como identificación de unas personas que exige la exclusión de otras, los derechos sólo se vienen proclamando como universales (digo 'proclamando', no necesariamente respetando) desde las revoluciones liberales.”(RUIZ MIGUEL, 2008, p. 1121)

xviic $P$ or eso se postula en la Enciclopedia la existencia de un derecho natural a la emigración, porque a nadie se le puede obligar a ser ciudadano de un Estado por la fuerza. Toda persona tiene derecho al cambio de ciudadanía [...] De ahí que existan dos modalidades de ciudadanía: la originaria, que surge con el nacimiento, y la adquirida, que procede de manifestaciones expresas de voluntad." (PÉREZ LUÑO, 2002, p. 184)

xviii As Constituições seguintes $(1804,1814,1830,1848,1852,1870,1875,1946,1958$ e a revisão de 1962) não iriam mais disciplinar a matéria. A concepção de cidadania adotada pelo Código napoleônico (1804) afastou-se da concepção do período do auge da Revolução Francesa. Este Código fortalece a noção estabelecida pela Constituição de 1799, na medida em que os pressupostos da liberdade e da igualdade são neutralizados politicamente.

xix،As eleições antigas nunca foram mecanismos de representação, pois os eleitos agiam sempre em nome próprio. Ao se construir, no entanto, o sistema representativo moderno, pôs-se desde logo uma dificuldade política de monta: em nome de quem deve o representante falar e agir? Se é em nome dos que o elegeram, a sua 
posição em nada difere, substancialmente, da do mandatário privado; ele deve, portanto, seguir rigorosamente as instruções do mandante e pode ter seus poderes por este revogados a todo tempo." (COMPARATO, 1993, p. 90)

xx"Pois bem, a esses direitos singularmente limitados de manifestação da liberdade política os primeiros constituintes franceses atribuíram a qualificação paradoxal de 'cidadania nova'; no que foram fielmente imitados pelo constituinte brasileiro de 1824. Segundo dispôs a nossa Carta imperial, 'as nomeações dos Deputados e Senadores para a Assembléia Geral, e dos Membros dos Conselhos Geraes das Províncias, serão feitas por Eleições indirectas, elegendo a massa dos Cidadãos activos em assembléias Parochiaes dos eleitores de Província, a estes os Representantes da Nação, e Província' (art. 90).” (COMPARATO, 1993, p. 91)

${ }^{x x i}$ Esse Estado “[...] configurou a infra-estrutura para uma administração disciplinada pelo direito, além de oferecer a garantia para um espaço de ação coletiva, livre do Estado. [...] criou a base para a homogeneidade cultural e étnica que permitiu, desde o final do século XVIII, a democratização do aparelho do Estado - mesmo que às custas da opressão e da exclusão das minorias nacionais. (HABERMAS, 1997, p. 281)

xxii، A história do surgimento do Estado nacional reflete-se na história do conceito de 'nação'. Entre os romanos, 'natio' é a deusa da origem e do nascimento. Ao contrário da 'civitas', a 'natio', do mesmo modo que 'gens' e 'populus', refere-se a populações [...] que ainda não se organizaram em associações políticas. Segundo este uso clássico, as nações são comunidades que [...] ainda não se encontram integradas politicamente através de uma organização estatal. A 'nação' mantém este significado durante a Idade Média. No século XV, ela se introduz nos idiomas populares. O próprio Kant afirma: 'A massa que se reconhece unida através da descendência comum, formando uma totalidade civil, deve ser chamada 'nação' (gens)'.’(HABERMAS, 1997, 282)

${ }^{x x i i i}$ Segundo Habermas, o desenvolvimento do conceito de cidadania deve ser tributado ao conceito de autodeterminação de Jean-Jacques Rousseau. A soberania do povo deveria ser compreendida como auto-legislação e inversão da soberania do príncipe, fazendo com que a autoridade política perdesse o seu caráter de poder natural. (1997, p. 284)

${ }^{\text {xxiv }}$ Sobre a posição de Luigi Ferrajoli ver também CADEMARTORI, Daniela M. L. de; CADEMARTORI, Sergio U. Mutações da cidadania: da comunidade ao Estado liberal. Revista Seqüência, Curso de PósGraduação em Direito da UFSC, Florianópolis, v. XXVII, n. 55, p. 65-94, dez. 2007.

xxv “'A jurisdição da Corte Européia toma como princípio orientador 'cinco liberdades do mercado comum', e interpreta como direitos fundamentais a livre troca de bens, a liberdade de domicílio dos trabalhadores, o direito de domicílio dos empresários, a liberdade da troca de serviços e a liberdade de movimentação do capital. [...] $\mathrm{O}$ novo nível de interdependências econômicas deixa prever uma necessidade crescente de coordenação para outros campos da política, tais como a política do meio ambiente, a política de impostos, a política social, a política de formação, etc. [...] Até agora, essas tarefas foram cumpridas por organizações européias que se configuraram numa rede administrativa cerrada e complexa. Formalmente, as novas elites funcionais permanecem ligadas aos governos e instituições de seus países de origem; de fato, porém elas já se emanciparam dos contextos nacionais. Pois funcionários que trabalham profissionalmente formam uma burocracia distanciada dos processos democráticos." (HABERMAS, 1997, p. 291-293)

xxvic‘Ou será que, nessas burocracias que trabalham conforme critérios de racionalidade econômica, se desenha apenas, de forma mais nítida, um desenvolvimento que há muito tempo não cessa de se expandir incontrolavelmente no interior dos Estados nacionais, ou seja, o fato de que os imperativos econômicos se tornam independentes e a política se estatiza, desmentindo a pretensão republicana e solapando o status de cidadão?" (HABERMAS, 1997, p. 292)

${ }^{x x v i i}$ Ver item 3.1.

xxviii Para explicar o exercício dos direitos políticos que integram o conteúdo da cidadania nas sociedades democráticas, Pérez Luño recorre à tese daquele que ele considera "o mais qualificado intérprete da cidadania liberal: John Rawls." Na obra O Liberalismo Político, Rawls tentou retificar sua concepção de "sociedade bem ordenada" (exposta em sua obra anterior Teoria da Justiça) na qual os princípios da justiça são estabelecidos sem a contaminação de interesses particulares e concretos, através da hipotética situação do "véu da ignorância". Em $O$ Liberalismo, ele parte da idéia de que o pluralismo das visões de mundo é um dos elementos essenciais dos Estados de Direito, tanto teórica quanto politicamente, inspirando a ordem interna, bem como a ordem das relações internacionais. Ora, afirmar que o liberalismo político é uma doutrina "construtivista", significa dizer que "los valores etico-políticos son resultantes de un proceso de construcción que la razón práctica lleva a cabo a partir de la concepción compleja de la persona y de la sociedad que permite establecer la idea do que se considera razonable." Para assegurar a coexistência de uma pluralidade de visões de mundo, o construtivismo político-liberal atua no sentido de se chegar a um "consenso por superposição" (overlapping consensus) entre doutrinas racionais que expressam diferentes visões religiosas filosóficas e morais. Este consenso tem, dentre as regras que limitam o seu funcionamento, a exigência de razão (burdens of reason), isto é, a necessidade de que os acordos e desacordos que se expressem através de argumentos racionais e que não sejam provocados pelo preconceito e pela ignorância. Para se chegar a esse tipo de argumentação é imprescindível que seja dado um papel central à educação cívica, instrumento capaz de levar ao consenso. (PÉREZ LUÑO, 2002, p. 203)

R. Fac. Dir. UFG, v. 37, n. 1, p. 73 - 93, jan. / jun. 2013

ISSN 0101-7187 
Nas sociedades liberais, a cultura política pública é o espaço em que se expressam diferentes doutrinas gerais que concorrem no debate político através do que Rawls chama de "estipulação" (estipulation), isto é, elas devem justificar-se em termos razoáveis. Para isso basta que elas atuem de acordo com a racionalidade prática baseada em argumentos razoáveis e persuasivos, não necessariamente precisam ser corretos do ponto de vista lógico ou mesmo estar sustentados por provas. Todavia, devem necessariamente partir dos princípios da boa-fé, da reciprocidade e da lealdade. (PÉREZ LUÑO, 2002, p. 204) 